\title{
Does the Age Profile of the Taxi Sector Labour Force in the Uk Affect the Provision of Transport for the Night Time Economy?
}

\author{
Moira Weir \\ Edinburgh Napier University
}

\begin{abstract}
Since the early 1990s it has been public policy in the UK to support the growth of night time economy (NTE), particularly through patronage of restaurants, clubs and pubs as a way of developing the use of city centres at night. This policy has had some success however, venue managers have stated that there is still room for further growth and key to this is improving the transport links to and from venues as the easier it is to get to and from a venue the more likely people are to attend events.

Following concern from venue managers that shortage of taxi supply at night was hampering the development of the NTE the London Chamber of Commerce investigated taxi services in London and found that there was a significant unmet demand for taxis at night. They suggested that this was caused in part by the age profile of taxi driver as most drivers were aged over 50 and this is the age group least likely to work at night.

This study uses data from the Labour Force Survey to find out if the age profile of London taxi drivers is similar to that of the taxi sector in the UK as a whole and assesses the impact this has on choice of working patterns. This work is coupled with a survey of taxi drivers operating in Scotland to find out directly why drivers choose to operate at certain times.
\end{abstract}

Key Words: Night Time Economy, transport, taxi, taxi driver

\section{Introduction}

Since the early 1990s it has been public policy in the UK to support the growth of the night time economy (NTE) as a way of developing the use of city centres at night (Hadfield, 2009a). This has involved encouraging the development of venues such as restaurants, clubs and pubs to help build a vibrant entertainment industry. This policy has had some success and the NTE is now worth over £66bn annually to the British economy (TBR, 2010). However, studies have indicated that there is still room for further growth and key to this is improving the transport links to and from venues (Roberts, 2005). Taxi services play a vital role in the provision of transport for the NTE as people like the flexibility and the door to door nature of the service. There has been some concern that there is a lack of supply at night which has hampered the growth of the NTE. For example, in 2005 the London Chamber of Commerce and Industry (LCC) investigated taxi services in London and found that there was a significant unmet demand for taxis at night. They suggested that this was caused in part by the age profile of taxi driver as most drivers were aged over 50 and this is the age group least likely to work at night.

This study uses data from the Labour Force Survey to find out if the age profile of London taxi drivers is similar to that of the taxi sector in the UK as a whole and assesses the impact this has on choice of working patterns. This work is coupled with a survey of taxi drivers operating in Scotland to find out directly why drivers choose to operate at certain times. 


\section{Background}

\subsection{The Night Time Economy}

The term Night Time Economy (NTE) first became prominent in the United Kingdom in the 1990s when it was used as a general term to describe the businesses and leisure pursuits that went to create city centre night life (Hadfield, 2009a). Bars, restaurants, night clubs and cafes were all viewed as venues which could offer entertainment and encourage people to socialise at night. Other venues such as concerts, cinema and theatres were also included as they attracted people to make trips to city centres in the evening and meant there were a variety of entertainment options available. As well as entertainment venues other services such as transport and fast food outlets were considered important industries which facilitated the NTE (Hobbs, 2003). In the 1990s the term NTE was quite loosely defined and this continues to be the case as leaving the actual activities involved in the NTE a little vague can be useful as it allows a large number of pursuits to be included and also allows for certain activities to grow or recede in popularity. However, it is important to note that while there are a whole range of activities which happen at night, such as health services, shift work, freight deliveries and so on, the term NTE specifically refers to the social activities which happen in city centres from early evening onwards (GLA, 2007).

\subsection{The Growth of the NTE in the UK}

The idea of the NTE became particularly prominent in the United Kingdom in the 1990s when successive governments were keen to regenerate town centres, many of which had become deserted outside normal retail hours (Roberts, 2005). It was quickly found that town centres' economies operated differently at night to during the day. The day time economy was centred round retail and office work with a peak of people arriving at around 9 am and leaving at 5 pm (Bromley et al., 2003). In the evening city centres had a greater focus on leisure activities, such as going to the pub, theatre, or out to dinner (Allen and Blandy, 2004). In particular, the liberalisation of alcohol licensing in England and Wales allowed bars and cafes to open for longer and encouraged people to drink larger amounts of alcohol on a more regular basis. This proved to be most attractive to younger people who enjoyed the freedom of being able to relax and enjoy the city night life (Cabinet Office, 2003).

The NTE in the United Kingdom proved to be a growth area for business employing 1.3 million people and creating (in the region of) $£ 66$ billion a year in England and Wales alone (TBR, op. cit). However, as well as opportunities to make money the phenomenon of the 24 hour city, fuelled by alcohol, brought with it a number of social issues including theft, public disorder and violence (Roberts, 2005). In response to this various agencies including local authorities, NHS trusts and the police were expected to work together to regulate and control the night time economy and the government issued guidance on how best to manage the night economy (Roberts, 2005).

\subsection{Managing the NTE}

Since the 1990s town planners have found that it has become increasingly important to manage the NTE and a key aspect of this has been to define the time periods discussed within the NTE, as different times of nights can have quite different issues to manage.

The City of Sydney did considerable work on this issue and found that there were distinctive time zones within the NTE which offered different activities and attracted different consumers (City of Sydney, 2011). Early evening was seen as the time from 5pm $-7 \mathrm{pm}$ which attracted office workers and shoppers who were keen to socialise in cafes and bars before going home. Evening was seen as $7 \mathrm{pm}-11 \mathrm{pm}$ where there were a range 
of activities including cinema, theatre, evening classes and sports as well as bars and restaurants. Importantly, in Sydney, most people participating in the NTE at this time had gone home first and then travelled to the NTE venues. This is in contrast to those in the early evening who had gone directly from work or other activities. Night was thought of as $11 \mathrm{pm}$ to $2 \mathrm{am}$. At $11 \mathrm{pm}$ the range of activities reduced and venues providing alcohol and music dominated. The provision of food and other sorts of entertainment lessened at this time and the clientele also changed as the age range present narrowed as older people left and younger people arrived. Late night started after $2 \mathrm{am}$ and the clientele changed again with a higher proportion of people engaged in the NTE being much drunker and more unsafe after $2 \mathrm{am}$. From 2am - 4am was noted a key time for accidents and crime.

Looking at the NTE as a series of activities which attract different types of people at different times rather than one entity can be helpful when planning the management of cities at night (Roberts, 2009). It can also be key to understanding the provision of transport for the NTE.

\subsection{Transport and the NTE}

Transport has been identified as key to the development of the NTE as there is a belief amongst venue managers that the easier events are to get to (and away from) the more likely people are to attend (Hadfield, 2011). For example, the $\mathrm{O} 2$ is a major venue in London which is known for attracting top performers however, its venue management has identified lack of taxi transport as a major disincentive for people considering attending events (TfL, 2012).

For those that do choose to participate in the NTE, transport is considered important as long queues at bus stops or taxi ranks can lead to confrontation as people wishing to get home compete for scarce resources (Hadfield, 2009a). Waiting for transport late at night on the street can leave people isolated and vulnerable to attack and this is a source of concern to the public, community safety teams and the emergency services.

Although providing transport for those participating in the NTE is considered important it does pose particular challenges which means it is not always a popular choice or priority for transport providers. Low density of passengers coupled with sudden peaks in demand can be difficult to provide for. Passenger behaviour can also cause concern as a mixture of tiredness and alcohol can lead to poor decision making or even violent confrontation.

\subsection{Stakeholders in the Provision of Transport for the NTE}

To understand the provision of transport for the NTE, the first step is to identify the key stakeholders that want an effective NTE transport system. The different stakeholders within the NTE have different needs from the transport system and it is helpful to look at each in turn.

The public - The general public has an interest in the provision of transport for the NTE although different groups within this broad heading have different agendas.

The first interested party is that of people wishing to participate in the NTE. This group is often aged under 30 years and looking to socialise and have fun (Roberts, 2005). The priority of this group in terms of transport is to ensure that it is possible to both get to venues and return home in a safe and cost effective manner. Allied to this group are the parents (or other carers) of those going out. Newspapers and other media provide some evidence that family members have a keen interest in ensuring that people are safe when out socialising and can play an important role both in providing transport and/or paying for it. However, the role of parents and carers in the provision of transport for the NTE has not featured either in academic literature or best practice guidance. A third section of the public that has an interest in the provision of transport for the NTE is that of residents 
of city centres. While this group may not wish to use the transport themselves, they have a keen interest in preventing the noise and crime that can be associated with people leaving venues. Taxi ranks and bus stops can be flash points for violence and antisocial behaviour as groups of people mill about waiting for transport to arrive and residents have an interest in ensuring this behaviour does not impact on their daily lives (Hobbs, op.cit). A fourth group within this heading is that of tourists. People who visit a city centre for a weekend have less local knowledge than those who attend city events on a regular basis. Roberts (2009) paid attention to tourism in the NTE as tourists are increasingly attracted to cities for weekend breaks where they plan to socialise and enjoy the entertainment on offer. In particular she looked at the phenomenon of stag and hen parties where single sex groups of friends visit a city to celebrate the upcoming marriage of one of the group members. This can have particular issues for city planners as visitors to a city may be even more vulnerable than local people as they do not know their way around.

City Planners - Throughout the UK there are different planning policies operating in different areas but all give some thought to the development of commercial activities including the entertainment industry. Transport plays an important role within the management of the NTE as it allows people to get to and away from venues. When thinking of developing the NTE planners would need to consider the effect any new development would have on the transport network in terms of congestion and noise.

Venue Management -transport is important to venue managers as they wish to attract people to their events and the easier events are to get to (and away from) the more likely people are to attend (Hadfield, 2011). In addition if a venue is known for creating noise and disturbance at night then this can affect its licensing agreement with the local authority and result in the venue losing its right to provide alcohol and/or entertainment. Therefore, it is in venue managements' interests to have a transport system that allows for rapid dispersal of patrons following closing time as this is the best method of avoiding the public disorder associated with queues at bus stops and taxi ranks at night (Hobbs, op. cit).

Community Safety Teams are part of Scottish Local authorities and work towards creating a safer community. Aspects which come under this work include crime prevention and safer travel therefore Community Safety Teams often take a particular interest in improving the safety of those coming home at night. For example, in 2009 2010 the Scottish Government established the Safer Streets fund which provided $£ 400$ 000 for Community Safety Partnerships across all 32 local authority areas. The money was targeted at improving safety at night and had a focus on improving CCTV coverage and providing taxi marshals at busy taxi ranks (Scottish Government Website, 2012). Therefore community safety teams look to transport to provide safe travel for passengers in order to enhance public safety.

Police and other emergency services - the police and other emergency services value effective transport as the quicker streets are cleared after venues close the less accidents, crime and disorder they have to deal with (Kirby \& Hewitt, 2011).

Transport providers - transport providers are also stakeholders in the provision of transport for the NTE. In some ways the agenda of transport providers is quite different to that of other stake holders as while all the other groups are clear they would like efficient, affordable transport providers are not always keen to operate. This is partly because the transport providers have concerns about public behaviour as well as other concerns about a lack of profitability. 


\subsection{Modes of Transport for the Night Time Economy}

There is not a lot of academic research on choice of transport modes for the NTE. However, as part of a study on the use of alcohol in the NTE, Moore (2007) asked how people intended to get home. The author conducted surveys with those participating in the NTE over 6 weekends spread across one year in Cardiff. What he found was that the breakdown of transport home was as follows:

\section{Transport mode used to get home by people participating in} the NTE over a weekend in Cardiff, Wales

drawn from Moore, 2007

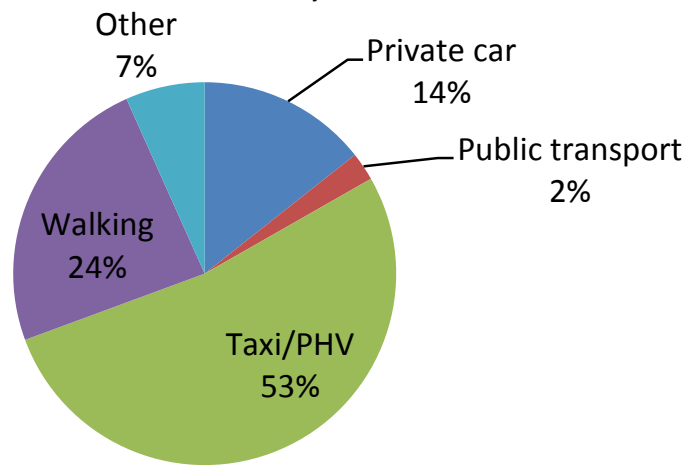

This shows that taxis/PHV, walking and private cars are all important modes of transport in the NTE. The use of public transport such as night buses was particularly low in this study which may indicate either a lack of such service or a definite preference for other modes of transport.

Moore found that about a quarter of trips made in the evening/night or for the NTE were done on foot. Walking can be an attractive option for the NTE as it is cheap and the walker is in complete control of when he or she decides to travel. There are some negative aspects though. Walking at night, particularly alone, can leave a person feeling vulnerable to crime and this sense of vulnerability increases the later it gets (Sheard, 2011). Fashion choices can also be a factor in determining whether or not to walk. Women wearing high heels may find it difficult to walk home and removing shoes can be hazardous if there is broken glass on the pavement or road (Roberts, 2005). The distance involved can be a key factor in choosing whether or not to walk as can the weather. As yet, there does not appear to be much data available on how distance or weather affects choice to walk for the NTE as most literature focuses on the vulnerability to crime associated with walking.

The private car can prove to be a convenient method of travel for the NTE either by the person driving themselves or receiving a lift. Access to a car, parking and weather conditions all contribute to a person's decision to choose to use a private car to travel to and from the NTE. Availability of other modes and distance involved can also contribute to the decision. However, perhaps the main factor involved in car use is that of alcohol. If a person chooses to drive a car to the NTE he or she will not be able to drink alcohol. Of course some people choose to ignore the drink driving laws and this dangerous practice is a source of concern to the public, police and those tasked with ensuring community safety (VPAWG, 2007). It also underlines the importance of an efficient, high quality public transport/taxi transport provision to the NTE in order to discourage such practices.

Bus operators in the UK (outside of London) are expected to run on a commercial basis. To do this they need a certain volume of customers using each service. Providing services for the NTE can prove to be unprofitable if there are not enough people using them and for the bus sector, the financial incentive is not so great as the costs involved in 
providing buses for a few people are high and often local authorities find they have to subsidise night bus services in order that they run at all (Transport Xtra, 2011). In addition a major practical concern for bus operators is that of passenger behaviour. Passengers who are under the influence of alcohol and/or tired after a night out can become abusive to staff or other passengers. In addition, passengers are more likely to get involved with fights or damaging property at night than during the day (Hobbs, op. cit).

Moore (op. cit) found that $55 \%$ of people questioned for his survey were planning to use a taxi or private hire car to get home after a night out. This is a particularly high rate of taxi use and caution should be used when discussing it as this finding may not be the same across the UK. It does nevertheless highlight the importance of the taxi sector in the provision of transport for the NTE. Moore's study did not break down the preferred mode of transport into time of night. However, the work done by City of Sydney did show that at different times of night different transport modes became more popular. So, for example in early evening the train was an option as were buses. However, the later it became the more likely it was that people would use taxis to get home and certainly by late night such as $2 \mathrm{am}$ or 3am the taxi was the most popular mode of transport (City of Sydney, op.cit).

The increase in demand for taxis at certain times is a particular feature of the taxi sector. The Department for Transport (DfT, 2010) highlighted the issue of peaked demand, stating that demand for taxis increased out with normal day time hours and peaked on Friday and Saturday nights. The DfT also noted that the demand for taxis at these times was not always met.

When thinking of why there may be a shortage of taxi transport at certain times, the first step is to look at how the taxi sector is regulated. In the United Kingdom the regulation of the taxi industry is a devolved issue with different rules applying in different parts of the UK and sometimes different parts of the same administrative area (Office of Fair Trading, 2003). There are some general issues which emerge when looking at the regulation of taxis, in particular issues surrounding the quality of drivers and vehicles, fare setting and the quantity of taxis allowed to operate in an area. However, different areas take quite different approaches to the management and regulation of the taxi sector and all still seem to face the problem of peaks in demand and consequently a lack of supply at key times. Therefore, regulation does not seem to be key in creating the problem. For example, in Scotland, England and Wales local authorities may choose to restrict the number of taxis operating in their area and some choose to do so. It has been argued that removing this restriction would allow the taxi sector to reach equilibrium where supply and demand are matched (Barrett, 2010). However, in practice the lack of taxi supply has been noted in areas where there are no restrictions on the number of taxis allowed to operate. For example, in London there are no quantity controls but a shortage of taxi transport has been a source of concern to the London Chamber of Commerce and Industry (LCC, 2007). Similarly the regulation of price or quality does not seem to fully explain shortages in taxi transport. For example, in London taxi drivers must undertake a stringent qualification known as The Knowledge before they can operate which some have suggested contributes to the lack of supply of taxi drivers at night. However, even in areas where the qualification is less difficult to achieve peaks in demand and shortages of supply have been noted. Equally different areas set taxi tariffs at different rates but still have the common problem of peaks in demand and shortage of supply.

\section{Problem Statement}

It has been established that in the UK there are peaks in demand for taxi transport centred around Friday and Saturday nights (DfT, Op Cit). The lack of taxi transport causes concern to a number of different stakeholders as it has been linked to accidents, crime and confrontation as people are left waiting for transport. In addition venue 
managers have expressed concern that getting home leads some people to choose not to go out and participate in the NTE.

The LCC looked into this issue and suggested that the age profile of taxi drivers had something to do with the shortage of supply as they found that drivers aged over 50 years were particularly unlikely to operate at night and those aged under 30 years old more willing to do so. As most drivers operating in London were aged over 50, for the LCC, this helped explain the lack of supply at night. (LCC, op. cit). This paper uses data from the Labour Force Survey (LFS) to assess if the findings of the LCC of characteristics of London taxi drivers are reflected in the United Kingdom as a whole. In addition the views of taxi drivers in Scotland were canvassed to find out if they avoided providing transport for the NTE and if so why.

\section{Identifying Sources of Data}

As the taxi sector is a regulated industry in the UK information on every registered taxi driver is kept with individual licensing bodies. However, this information is not freely available for research purposes and as there are approximately 400 individual licensing bodies within the UK it was felt that approaching each on an individual basis would prove to be expensive and time consuming for possibly scant response. Instead it was decided to use data which was freely available and the Labour Force Survey was the first choice as it is nationally collected and provided reliable data over many years.

\subsection{Labour Force Survey}

The Labour Force Survey is the largest household survey in the UK and provides information on people's personal and working lives (Office for National Statistics, 2011). The LFS is undertaken by the Office for National Statistics and questions 60000 households on a quarterly basis. Once a household has been identified and agrees to participate in the survey they are contacted for five successive quarters. This means that the data gathered covers one full year of the life of the participant. Most participants are interviewed face to face in the first instance and then undertake telephone interviews for the next four quarters.

The survey provides information on the types of employment that people undertake in the UK and working patterns. It also includes information on salaries, disability and qualifications to give a rounded picture of economic activity in the UK. Although the survey is commissioned by the UK government the data that it generates is widely disseminated and this research makes full use of the data available, although the study is still at an early stage of development.

The LFS is undertaken on a quarterly basis which means that four separate data sets are compiled each year. These databases need to be pooled if data is to be compared from different quarters.

An initial look at the LFS data showed that on average 330 taxi drivers were interviewed each year and in total 3343 taxi drivers were interviewed from 2002-2011. In $2010 / 2011$ the total population of taxi/phv drivers was 356000 so each sample represented $0.1 \%$ of the entire population.

\subsection{London Chamber of Commerce and Industry Study}

The LFS combines taxi and phv drivers into one category and it is not possible to separate them out into individual components. This means that the different types of taxi service must be looked as a whole and comparisons between taxi and phv drivers cannot be made using this data source. The LCC study included interviews with 200 taxi drivers and 50 private hire car operators this means that both types of services were represented but in different ways. Thus while it is possible to draw some comparisons between the 
LCC findings and the data provided by the LFS, caution does need to be taken when discussing results as the methodologies used are different.

To canvas taxi drivers' views, a structured interview was drawn up to gain more information from taxi drivers about their views on night time working and the night time economy. The structured interview was conducted with seventy five taxi drivers across five local authority areas in Scotland.

\section{Findings}

\subsection{Findings from the Analysis of the Labour Force Survey}

The data drawn from the LFS on taxi driver samples from 2002-2011 was compiled into a database and used to draw a picture of characteristics of those driving in the taxi sector in the UK. Variables to do with age showed that most drivers in the UK are aged over 35 years. The age of taxi drivers has remained fairly constant over the period of the study. Taxi/phv drivers aged under 30 years made up a small proportion of the overall taxi workforce. Across the whole period reviewed, the average age of taxi drivers was 48 years. This compares to an average working age of all work sectors of 41 suggesting ages in the taxi sector are a little above the norm. The age difference becomes more marked when focussing on those that work in the NTE, as 78\% of bar staff were aged under 35 as opposed to $16 \%$ of taxi drivers.

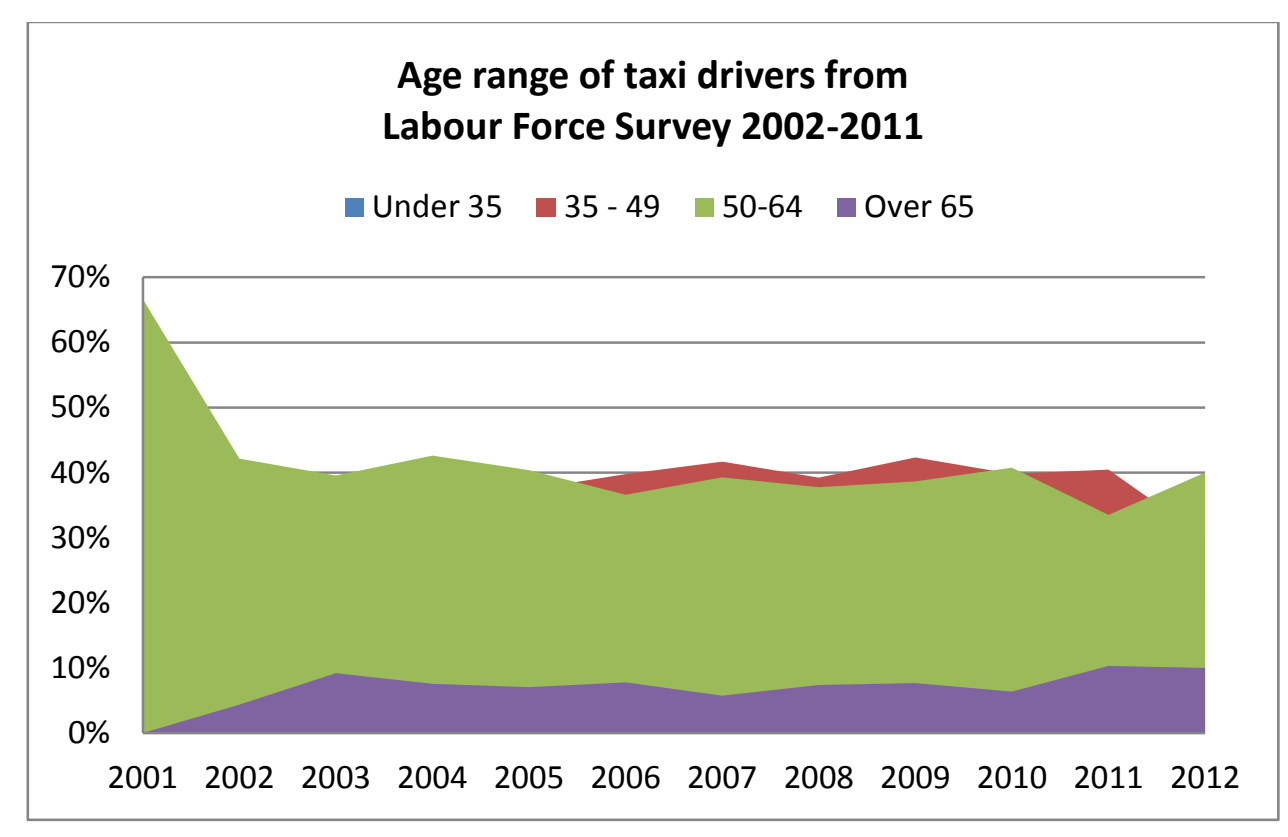

This supports the LCC finding of 2005 that most taxi drivers are aged over 30 years.

The LFS data showed that most taxi/phv drivers in the survey working in the UK worked a variety of shifts. Evening shift was defined as $5 \mathrm{pm}$ to midnight and night work was shifts that extended beyond midnight. Drivers aged under 35 were slightly more likely to opt to work permanent night or evening work although in all aged groups most drivers worked a variety of shifts. 


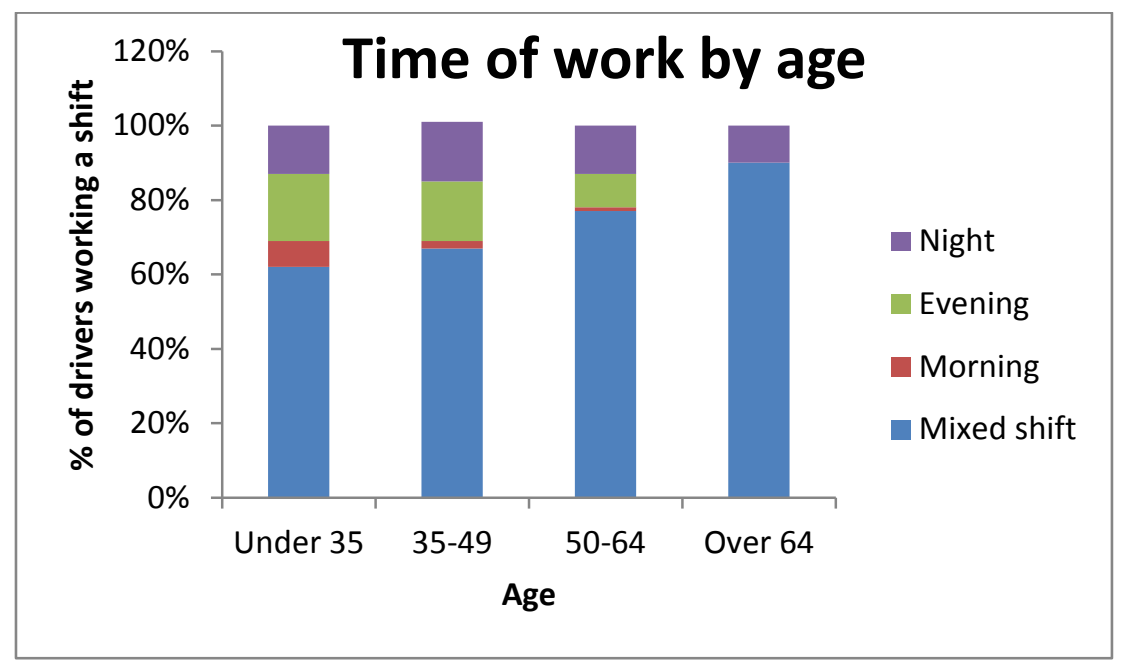

The LCC study highlighted that less than one fifth of London taxi drivers in the survey worked later than $9 \mathrm{pm}$ once per week. This was more difficult to look at on a national basis as while the LFS does ask about shift patterns the questions are framed in a different way which does not lend itself to direct comparison. The LFS data suggested that the vast majority of taxi drivers of all ages worked a variety of shifts and it was not possible to tell in such detail how often they worked one particular shift over another. However, there is certainly no evidence to suggest that the LCC findings are not applicable to the UK in general, although more research is required in this area.

The LCC also found that age had a significant impact on the times that taxi and phv drivers chose to work. The LFS data highlighted that the age group most likely to choose to work permanent evening or night shifts were those aged under 35 and those least likely to do so were those aged over 50 . This means that there may be some validity in the idea that age affects when drivers choose to work however, due to the nature of the data, the findings were not stark and so direct discussion with taxi drivers was necessary to further investigate the issue.

\subsection{Findings from Survey of Taxi drivers in Scotland}

To find out more about why taxi drivers chose to work certain working hours structured interviews were undertaken with 75 taxi drivers in Scotland. The results of the structured interviews showed that drivers had reservations about working at night. $98 \%$ of those interviewed said they believed that taxis played a very important part in the provision of transport for the night time economy. Despite this $38 \%$ avoided working at night and of these 74\% said they avoided working at night because of concern about their personal safety. $15 \%$ of drivers avoided working at night due to other commitments and the other reasons were given as not having access to a taxi $(6 \%)$ or did not believe they would make money at that time (3\%). $73 \%$ of drivers reported that they had been made to feel unsafe by a passenger at least once in the previous year and $90 \%$ of incidents where drivers were made to feel unsafe occurred either in the evening or at night. The sense of concern about certain passengers' behaviour was found across all age groups. However, older taxi drivers were more likely to respond to this concern by avoiding working at night.

When taxi drivers were asked about their experience of crime while at work, $88 \%$ said they had experienced threats and abuse at least once in the past year and $98 \%$ had experienced passengers attempting to dodge paying the fare. Other crimes such as robbery or assault were far less common. 
Those taxi drivers who reported that they had been made to feel unsafe by a passenger at least once in the previous year were asked some supplementary questions about this. $42 \%$ of drivers said the person who made them feel unsafe was male, $5 \%$ said the person was female and 53\% said it was both males and females. Drivers were clear that female passengers could be as threatening as male passengers. All taxi drivers reported that the person who made them feel unsafe was under the influence of alcohol. The general public's abuse of alcohol played a major part in drivers' reluctance to work in the evening. $66 \%$ of taxi drivers who participated in the survey had reported an incident they had experienced while working as a taxi driver to the police. Of these $20 \%$ said this had resulted in a prosecution. Many drivers stated that they had reported incidents at the beginning of their career but after some time in the job had stopped doing so. The most common reason given for not reporting an incident, at $50 \%$ of participants, was that there was no point as nothing would happen. A further $20 \%$ said that the process of reporting crime was too time consuming and $17 \%$ said they would not report a crime as it would mean they would lose money on their shift. $13 \%$ had never had a reason to report a crime. The lack of reporting of crime by taxi drivers means that even if the police or Office for National Statistics were to include crime against taxi drivers in their work place crime statistics it is unlikely the true level of crime would be reflected.

All those that participated in the survey were asked their age which was banded in groups of $18-25,26-45,46-65$ and over 65 . The analysis of the data showed that $39 \%$ of those who participated in the survey were aged 45 or under and of these $31 \%$ avoided working at night. Nobody in the 18-25 age group ( 2 people) avoided night work. $61 \%$ of those that participated were aged over 45 and of these $52 \%$ avoided working at night which does point towards age being a factor in determining when individual taxi drivers choose to work - calculation of a chi square statistic shows this to be significant at the $10 \%$ level. This shows that there does seem to be a tendency towards older drivers choosing not to work at night. However, when questioned taxi drivers do not mention age as a factor but focus on other issues such as personal security. Perhaps this could be explained by older taxi drivers having greater concern about personal security than younger drivers.

\section{Conclusion}

Town and city centre management at night is an important issue in UK policy as a whole. In some areas the development of the night time economy is considered key to the regeneration of town and city centres and it is widely accepted that safe and efficient transport options can help with this. Taxis and private hire cars have been identified as offering flexible, affordable and safe transport at night. However, some areas have noted that there is a shortage of taxi services at night and have linked this to the age of drivers. It has been suggested that drivers aged over 50 are less willing to operate at night.

This study used data from the LFS to look the age profile of taxi drivers in the whole of the UK and found that $45 \%$ to $50 \%$ of taxi drivers were aged over 50 years old. The data from the LFS also suggested that there is some evidence that drivers aged over 50 years are less likely to work permanent evening or night shift than those aged under 35 although more work needs to be undertaken in this area before any firm conclusions can be drawn.

The views of taxi drivers in Scotland were canvassed and this revealed that drivers had concerns about personal security while working at night and so behaviour of passengers seemed to be a greater disincentive to work at night, and that this view was more prevalent in older drivers. The survey also confirmed the findings of the LCC and the LFS data that older drivers were less likely to choose to work at night. 


\section{References}

[1] Allen and Blandy, "The Future of City Centre Living: Implications for Urban Policy”, Sheffield Hallam University, Centre for Regional Economic and Social Research, (2004).

[2] S. D. Barrett, "Regulatory capture, property rights and taxi deregulation: a case study", Institute of Economic Affairs, vol. 23, vol. 4, (2003), pp. 34-40.

[3] S. D. Barrett, "The sustained impacts of taxi deregulation", IEA Economic Affairs, vol. 30, (2010), pp. 61-65.

[4] R. Bromley, A. Tallon and C. Thomas, "Disaggregating the space time layers of city centre activities and their users", Environment and Planning A, vol. 35, (2003), pp. 1831-1851.

[5] Cabinet Office, Alcohol Harm Reduction Strategy for England, London, (2003).

[6] City of Sydney, "Open Sydney: Future directions for Sydney at night", Sydney, City of Sydney, (2011).

[7] Department for Transport, Taxi and Private Hire Vehicle Licensing: Best Practice Guidance, www.dft.gov.uk/publications/taxi-private-hire-licensing, (2010).

[8] Greater London Authority, "Managing the night time economy: Best Practice Guidance", London, Greater London Authority, (2007).

[9] P. Hadfield, S. Lister and P. Traynor, "This Town's A Different Town Today", Journal of Criminology and Criminal Justice, vol. 9, no. 4, (2009), pp. 465-485.

[10] P. Hadfield, "Night Time Economy Management, International Research and Practice, A Review for the City of Sydney", Sydney, City of Sydney, (2011).

[11] P. Hadfield, "Nightlife and Crime: Social Order and Governance in International Perspective", Oxford, Oxford University Press, (2009).

[12] D. Hobbs, P. Hadfield, S. Lister and S. Winslow, "Bouncers: violence and governance in the night-time economy", Oxford, Oxford University Press, (2003).

[13] S. Kirby and L. Hewitt, "The impact of the Licensing Act 2003 on drinking habits, offences of crime and disorder, and policing in England's newest city", Safer Communities, vol. 10, no. 1, (2011), pp. 3138.

[14] London Chamber of Commerce and Industry, "The London Taxi Trade", London, London Chamber of Commerce and Industry, (2007).

[15] S. Moore, J. Shepherd, N. Perham and B. Cusens, "The prevalence of alcohol intoxication in the nighttime economy", Alcohol and Alcoholism, vol. 42, no. 6, (2007), pp. 629-634.

[16] Office of Fair Trading, "The regulation of licensed taxi and PHV services in the UK", Office of Fair Trading Office for National Statistics (2011), Labour Force Survey: User Guide Volume 1 - LFS Background and Methodology Version 1.0, Office for national Statistics, London, (2003).

[17] M. Roberts, "Good Practice in Managing the Evening and Late Night Economy: A Literature Review from an Environmental Perspective", London, Office of the Deputy Prime Minister, (2004).

[18] M. Roberts, "How to Manage Town Centres", London, Office of the Deputy Prime Minister, (2005).

[19] M. Roberts, "From 'creative city' to 'no-go areas' - The expansion of the night-time economy in British town and city centres", Cities, vol. 23, no. 5, (2006), pp. 331-338.

[20] M. Roberts and A. Eldridge, "Planning the Night Time City", London, Routledge, (2009).

[21] Scottish Government, "Alcohol" Scottish Government website, available at http://www.scotland.gov.uk/Topics/Health/health/Alcohol, extracted (2011) November.

[22] Scottish Government, Funding for Safer Streets, extracted from Scottish Government website 20 March 2012 http://www.scotland.gov.uk/News/Releases/2009/09/22095854, (2012).

[23] L. Sheard, "Anything Could Have Happened: Women, the Night-time Economy, Alcohol and Drink Spiking", Sociology, vol. 45, no. 4, pp. 619-633.

[24] TBR, "Night Mix News", available on website at www.tbr.co.uk/index.php?id=27 extracted 10 May (2011).

[25] The Telegraph (2012), "Taxi drivers and the importance of The Knowledge, 6 August 2012 and available on the web at www.telegraph.co.uk/motoring/news/9421234/Taxi-drivers-and-the-importanceof-The-Knowledge.html, accessed on 20 March 2013

[26] Transport Xtra, Bristol Replaces Night Buses with Taxi Sharing, Issue 5834, (2011) November.

[27] Transport for London, $\mathrm{O} 2$ - Keep Cabbies Coming, presentation on a loyalty scheme for London taxi drivers to resolve a taxi shortage at The O2, delivered at London Transport Awards, (2012).

[28] Violence Prevention Alliance Working Group, Youth Violence, Alcohol and Nightlife, Fact Sheet 3 late night transport, Liverpool, Violence Prevention Alliance Working Group, (2007). 
International Journal of Transportation

Vol.3, No.2 (2015) 